"Do you love truth for truth's sake, and will you endeavour impartially to find and receive it for yourself, and communicate it to others ?" They should. in no way be blamed for not foreseeing every evil use to which their discoveries might be put; "those who decry science should come out into the open and say they prefer ignorance to understanding, darkness to light". Outside their scientific discoveries the mass of scientists are like the mass of other people with all the same human weaknesses and strengths. They should bear their moral responsibilities for the use or abuse of scientific discoveries with the rest of mankind.

\section{City and Guilds of London Institute}

In the seventy-fifth annual report of the City and Guilds of London Institute, attention is directed to the launching of the ninth examining body, now officially known as the Associated Examining Board, for the General Certificate of Education. The establishment of the Board has been welcomed as one of the most significant developments in secondary education in recent years and a development which should undoubtedly prove to be of far-reaching importance in both educational and industrial fields. The new body is the only one of the nine now examining for the General Certificate of Education on which industrial and professional interests are directly represented, and the Board has therefore had in mind the production of syllabuses and the introduction of new subjects suitable for students intending to enter industry and commerce. The Couneil also reports progress in the number of candidates taking City and Guilds examinations, and of further requests for training courses. The number of candidates who sat for the Department's examinations in 1954 totalled 88,560 -an increase of 6,273 over the previous year. Many new subjects were introduced during the year and major revisions of existing schemes were undertaken.

In the City and Guilds College the numbers of fulltime undergraduate and postgraduate students have risen considerably ; a chair of heavy electrical engineering and a readership in production engineering have been instituted, to be financed from the income which will be received from a share of the Counterpart Funds placed at the disposal of the University of London; and the first allocation of special expansion recurrent grant will allow for the appointment of a professor of applied science (engineering) and a professor of soil mechanics, in addition to other necessary additions to the lecturing staff.

\section{British Hat and Allied Feltmakers Research Association}

THE seventh annual report of the Director of Research of the British Hat and Allied Feltmakers Research Association (pp. $19+2$ plates; from the Association, Manchester, 1954) covers the year ended August 1954 and refers to the fresh conditions of grant obtained for the five years commencing in April 1954. For the first two years the government grant remains unchanged, but for the following three years the industry is asked to raise an annual minimum of $£ 12,000$ to attract grant at the rate of $£ 9,000$ a year, with up to a further $£ 5,000$ on the basis of $£ 100$ for each $£ 100$ in excess of the stipulated minimum raised by the industry. One of the Association's outstanding achievements has been the development of equations for carrotting fur, although further work and factory trials will be necessary to establish their validity for all grades of fur and different types of carrotting reagents. So far, different equations have been established for the standard 'mercury in nitric acid' reagent and for non-mercuric reagents of the 'hydrogen peroxide-nitric acid' type. The study of wool noil, of the directional felting of wool and the physical properties of fibres continued, and the operation of multi-roller machines in relation to the degree of carrotting and the grade of fur used was investigated. The survey of wool bumping machines has yielded information on the loading of crank bumpers in relation to the wetness and temperature of the mass, and to the rate of felting, which should find immediate application in the industry, while observations on the time of dyeing of wool felt were immediately reflected in the qualitv of the hats produced. Ad hoc research programmes included the blending of fur with protein fibres, the shower-proofing of hats and the stoving temperature in carrotting fur. Other work has been concerned with standardization of raw materials and finished products. A research conference held in conjunction with the annual general meeting, at which papers reviewing the work of the Association were delivered, was an outstanding success.

\section{Finnish Institute for Occupational Health}

THE Board of Trustees of the Institute of Occupational Health in Helsinki is made up of members of the Cabinet, the universities and voluntary organizations. Its funds are drawn from industry, insurance companies and workers' organizations and, each year, it publishes a report in English (Occupational Medical Foundation and Institute of Occupational Health. Annual Report, 1954. Pp. 47. (Helsinki : Occupational Medical Foundation and Institute of Occupational Health, 1955) ). Besides a general department, it has medical, physiological, psychological and industrial hygiene departments and, in 1954, the number of workers engaged on research projects increased substantially compared with the previous year. Among the original investigations carried out was one into the problem of sickness absenteeism among government workers. Of 44,000 government workers whose cases were examined, the frequency of sickness among groups working indoors has been three times higher than that among outdoor workers. A study of the characteristics of an influenza epidemic and of the effects of immunization showed that previous attacks of influenza had no clear immunizing effects, while the results obtained from immunization were unsatisfactory. Investigations were also made into the reasons why javelin throwers have to give up their sport each year for varying periods, while a statistical study was also made into the relation between age and number of traffic accidents incurred by some five hundred bus drivers. This showed that the number of accidents involving drivers with long experience diminishes with age up to approximately 45-48 years, after which the accident-rate begins to grow.

\section{Macaulay Institute for Soil Research : Report for 1953-54}

THE annual report for 1953-54 of the Macaulay Institute for Soil Research, Aberdeen (pp. $\mathbf{5 5 + 2}$ plates; from the Institute at Craigiebuckler, Aberdeen; 1955), indieates that the Institute continues actively to promote its aim of advancing the funda. mental study of the soil in all its aspects. The Pedology Department surveyed a further 260 square 